Check for updates

The BMJ

Cite this as: BMJ 2021;373:n1475 http://dx.doi.org/10.1136/bmj.n1475 Published: 08 June 2021

\title{
Covid-19: Aspirin does not improve survival for patients admitted to hospital, trial reports
}

Gareth lacobucci

Aspirin does not improve survival for patients in hospital with covid-19, the UK Recovery $\operatorname{trial}^{1}$ has reported.

The randomised trial, which is testing a range of possible treatments for people admitted to hospital with covid-19, studied the effect of aspirin in nearly 15 ooo patients between November 2020 and March 2021. Some 7351 patients were randomised to aspirin $150 \mathrm{mg}$ once daily and compared with 7541 patients randomised to usual care alone.

The results-released through a press release $^{2}$-showed no evidence that aspirin treatment reduced mortality. The team reported no significant difference in the primary endpoint of 28 day mortality (17\% aspirin $v 17 \%$ usual care; rate ratio 0.96 (95\% confidence interval 0.89 to 1.04$) ; \mathrm{P}=0.35$ ). The results were also consistent in all prespecified subgroups of patients.

Patients who were allocated to aspirin had a slightly shorter length of stay in hospital (median 8 days $v 9$ days), and a higher proportion were discharged from hospital alive within 28 days $(75 \% v 74 \%$; rate ratio 1.06; 95\% CI 1.02 to $1.10 ; \mathrm{P}=0.0062)$. Among patients who were not on invasive mechanical ventilation at baseline, the trial reported no significant difference in the proportion who progressed to invasive mechanical ventilation or death $(21 \% v 22 \%$; risk ratio 0.96; $95 \%$ CI 0.90 to 1.03; $\mathrm{P}=0.23$ ).

For every 1000 patients treated with aspirin, approximately six more patients experienced a major bleeding event and around six fewer experienced a thromboembolic (clotting) event, the study team reported.

The findings will shortly be published as a preprint and have been submitted for peer review.

Peter Horby, professor of emerging infectious diseases in the Nuffield Department of Medicine, University of Oxford, and joint chief investigator for the Recovery trial, said, "The data show that in patients admitted to hospital with covid-19, aspirin was not associated with reductions in 28 day mortality or in the risk of progressing to invasive mechanical ventilation or death. Although aspirin was associated with a small increase in the likelihood of being discharged alive this does not seem to be sufficient to justify its widespread use for patients admitted to hospital with covid-19."

Martin Landray, professor of medicine and epidemiology at the Nuffield Department of Population Health, University of Oxford, and joint chief investigator, said, "There has been a strong suggestion that blood clotting may be responsible for deteriorating lung function and death in patients with severe covid-19. Aspirin is inexpensive and widely used in other diseases to reduce the risk of blood clots, so it is disappointing that it did not have a major impact for these patients. This is why large randomised trials are so important-to establish which treatments work and which do not.”

Anthony Gordon, professor of anaesthesia and critical care, and NIHR research professor, Imperial College London, who was not involved in the trial, said the findings were "disappointing" but "important to know."

"Importantly there were no major safety concerns and so the Remap-Cap trial continues to evaluate aspirin and other similar drugs to prevent blood clots, in combination with other treatments in the sickest patients with covid-19 in intensive care," he said.

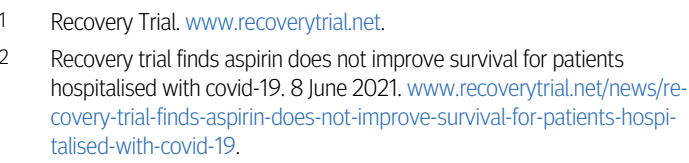

This article is made freely available for use in accordance with BMJ's website terms and conditions for the duration of the covid-19 pandemic or until otherwise determined by BMJ. You may use, download and print the article for any lawful, non-commercial purpose (including text and data mining) provided that all copyright notices and trade marks are retained. 